\title{
Structure and morphology of magnetite anaerobically-produced by a marine magnetotactic bacterium and a dissimilatory iron-reducing bacterium
}

\author{
N.H.C. Sparks ${ }^{1}$, S. Mann ${ }^{1}$, D.A. Bazylinski ${ }^{2}$, D.R. Lovley ${ }^{3}$, H.W. Jannasch ${ }^{4}$ \\ and R.B. Frankel ${ }^{5}$ \\ ${ }^{\prime}$ School of Chemistry, University of Bath, Bath BA2 7AY (U.K.) \\ ${ }^{2}$ Department of Anaerobic Microbiology, Virginia Polytechnic Institute and State University, Blacksburg, VA 24061 (U.S.A.) \\ ${ }^{3}$ United States Geological Survey, Reston, VA 2209 (U.S.A.) \\ ${ }^{4}$ Biology Department, Woods Hole Oceanographic Institution, Woods Hole, MA 02543, (U.S.A.) \\ ${ }^{5}$ Department of Physics, California Polytechnic State University, San Luis Obispo, CA 94307 (U.S.A.)
}

\begin{abstract}
Intracellular crystals of magnetite synthesized by cells of the magnetotactic vibroid organism, MV-1, and extracellular crystals of magnetite produced by the non-magnetotactic dissimilatory iron-reducing bacterium strain GS-15, were examined using high-resolution transmission electron microscopy, electron diffraction and ${ }^{57} \mathrm{Fe}$ Mössbauer spectroscopy. The magnetotactic bacterium contained a single chain of approximately 10 crystals aligned along the long axis of the cell. The crystals were essentially pure stoichiometric magnetite. When viewed along the crystal long axis the particles had a hexagonal cross-section whereas side-on they appeared as rectangules or truncated rectangles of average dimension, $53 \times 35 \mathrm{~nm}$. These findings are explained in terms of a three-dimensional morphology comprising a hexagonal prism of $\{110\}$ faces which are capped and truncated by $\{111\}$ end faces. Electron diffraction and lattice imaging studies indicated that the particles were structurally well-defined single crystals. In contrast, magnetite particles produced by the strain, GS-15 were irregular in shape and had smaller mean dimensions $(14 \mathrm{~nm})$. Single crystals were imaged but these were not of high structural perfection. These results highlight the influence of intracellular control on the crystallochemical specificity of bacterial magnetites. The characterization of these crystals is important in aiding the identification of biogenic magnetic materials in paleomagnetism and in studies of sediment magnetization.
\end{abstract}

\section{Introduction}

The bacterial production of magnetite has been considered as providing a possible significant contribution to the natural remanent magnetism of sediments $[1,2]$. In this respect, the crystal chemical properties of the biogenic minerals are of fundamental importance. Sediment-dwelling bacteria can produce magnetite $\left(\mathrm{Fe}_{3} \mathrm{O}_{4}\right)$ either intracellularly (magnetotactic bacteria [3]) or extracellularly (dissimilatory iron-reducing bacteria [4]). Magnetotactic bacteria, which inhabit both aerobic and anaerobic sediments, use membrane vesicles to produce magnetite particles of a narrow size range and species-specific morphology. In the magnetotactic spirillum, Aquaspirillum magnetotacticum, the magnetic particles are truncated octahedra [5], while in other bacteria, particles with morphologies based on hexagonal prisms $[6,7]$ and bullet-shaped or arrowhead geometries are known [8].

Recently, the first isolation and axenic culture of a marine, magnetotactic bacterium has been reported [9]. The organism, strain MV-1, has vibroid to helicoid morphology and can grow anaerobically with $\mathrm{N}_{2} \mathrm{O}$ as the terminal electron acceptor, or microaerobically using $\mathrm{O}_{2}$. MV-1 affords the first opportunity to compare the crystallochemical properties of magnetite produced intracellularly with magnetite particles deposited extracellularly by the dissimilatory non-magnetotactic iron-reducing bacterium, strain GS-15, both under anaerobic conditions. 
Cells of strain GS-15 use ferric iron as the terminal electron acceptor in their metabolism [4] The subsequent reaction of $\mathrm{Fe}(\mathrm{II})$ with residual ferric oxide results in magnetite deposition. In contrast with crystals formed in magnetotactic bacteria, no membrane vesicles or other organic structures are associated with this magnetite. Thus this process appears to be a biologically induced mineralization process, as opposed to the biologically controlled processes that occurs in the magnetotactic bacteria. In this paper, we compare and contrast the structural and morphological aspects of bacterial magnetites formed by the magnetotactic strain MV-1 and the dissimilatory iron-reducing bacterium, GS-15. We show that the crystallochemical properties and magnetic nature of the biogenic products are significantly different.

\section{Materials and methods}

Cells of strain MV-1 were grown anaerobically to late exponential phase (ca. $8 \times 10^{8}$ cells $\mathrm{ml}^{-1}$ ) in a diluted artificial seawater medium using $\mathrm{N}_{2} \mathrm{O}$ as the terminal electron acceptor. Ferric quinate [10] at $25 \mu \mathrm{m}$ was the principal source of iron in the growth medium. Cells grown under these conditions contain an average of 10 magnetic particles (magnetosomes) with magnetic accounting for about $1.5 \%$ of the dry weight of the cells [9].

Strain GS-15 is an obligate anaerobe and requires strict anaerobic culturing techniques. As previously described [11], all gases were passed through a column of hot reduced copper filings to remove traces of oxygen and all transfers were performed with syringes and needles that had been flushed with $\mathrm{O}_{2}$-free gas. An amorphous $\mathrm{Fe}$ (III) oxide was synthesized by neutralizing a 0.4 $M$ solution of $\mathrm{FeCl}_{3}$ to $\mathrm{pH} 7$ with $\mathrm{NaOH}$ followed by extensive washing with deionized water until the chloride concentration in the associated water was less than $1 \mathrm{~m} M$. The media contained ca. 200 $\mathrm{mmol}$ of the $\mathrm{Fe}$ (III) oxide per litre. Two buffer systems, phosphate $\left(4.3 \mathrm{~m} \mathrm{M} \mathrm{NaH} \mathrm{PO}_{4} \cdot \mathrm{H}_{2} \mathrm{O}\right)$ and carbonate (30 m $M \quad \mathrm{NaHCO}_{3}$ ), were studied. Medium constituents were: $\mathrm{CaCl}_{2} \cdot 2 \mathrm{H}_{2} \mathrm{O}(0.6$ $\mathrm{m} M), \quad \mathrm{KCl}(1.3 \mathrm{~m} M), \quad \mathrm{NH}_{4} \mathrm{Cl}(28 \mathrm{~m} M)$, $\mathrm{CH}_{3} \mathrm{COONa}(83 \mathrm{~m} \mathrm{M})$ and a mixture of trace minerals and vitamins [11]. The medium $(100 \mathrm{ml})$ was dispensed into serum bottles $(120 \mathrm{ml}$ capacity) and bubbled for at least 15 min with either $\mathrm{N}_{2}$ (phosphate-buffered medium) or $\mathrm{N}_{2}-\mathrm{CO}_{2}(80: 20)$ (bicarbonate buffered medium) to remove dissolved $\mathrm{O}_{2}$. The bottles were then capped and the medium sterilized by autoclaving $\left(121^{\circ} \mathrm{C} / 20 \mathrm{~min}\right)$. The $\mathrm{pH}$ of the autoclaved phosphate- and bicarbonate-buffered media were 7-7.2 and 6.7-6.8 respectively. Cultures were incubated at $33^{\circ} \mathrm{C}$ in the dark.

Whole cells of MV-1 and sonicated samples of magnetite produced by GS-15 were deposited on carbon-coated nitrocellulose-covered copper mesh electron microscope grids by air drying. A Jeol 2000FX analytical transmission electron microscope, fitted with a tungsten filament and operated at $200 \mathrm{keV}$ was used. Lattice images were recorded at a range of defocus values with an objective aperture of $80 \mu \mathrm{m}$. Electron diffraction patterns were recorded in the selected area and small probe (micro-diffraction) mode. Energy dispersive X-ray analysis (EDXA) was undertaken on individual crystal using a Link AN 10000 Lidrifted silicon detector. The analysis time was 100 s. Crystal dimensions were measured from TEM micrographs recorded at a magnification of $10^{5}$ and $0^{\circ}$ tilt angle by using a vernier caliper. Over 50 crystals were measured.

Cells of MV-1 were also grown with ferric quinate enriched in $\mathrm{Fe}-57$ for Mössbauer spectroscopy analysis. The ferric quinate was synthesized from $\mathrm{Fe}_{2} \mathrm{O}_{3}$ (95\% enriched in $\mathrm{Fe}-57$ ) by the method of Frankel et al. [12]. Cells were harvested anaerobically by centrifugation at $10,000 \mathrm{~g}$ for 20 min. at $4{ }^{\circ} \mathrm{C}$. All separation steps were performed at $4{ }^{\circ} \mathrm{C}$ under $90 \% \mathrm{~N}_{2}: 10 \% \mathrm{H}_{2}$ in an anaerobic chamber (Coy Laboratory Products, Ann Arbor, Michigan). Cells were washed twice with anaerobic $50 \mathrm{~m} M$ potassium buffer containing $18 \mathrm{~g} \mathrm{NaCl}$ per litre at $\mathrm{pH}$ 7.2. Cell paste was loaded into airtight plastic Mössbauer spectroscopy sample containers and sealed in the chamber. Spectra were obtained with a constant acceleration spectrometer and variable temperature dewar.

\section{Results}

Individual cells of strain MV-1 contained a single chain of approximately 10 anisometric magnetosomes aligned parallel to the crystal long axis (Fig. 1a). When viewed along the long axis the crystal had a hexagonal cross-section (Fig. 1b) 
while side-on the inclusions appeared as truncated rectangles of rectangles (Fig. 2). The length of the particles $(n=89)$ varied from 21 to $74 \mathrm{~nm}$ (mean value $53 \mathrm{~nm}, \sigma=10.86 \mathrm{~nm}$, Fig. 3a) while the particle width varied from 12 to $54 \mathrm{~nm}$ (mean $=35$ $\mathrm{nm}, \sigma=7.86 \mathrm{~nm}$, Fig. 3b). A linear relationship $(p<0.001)$ between the length and width was determined for all particles measured (Fig. 3c).

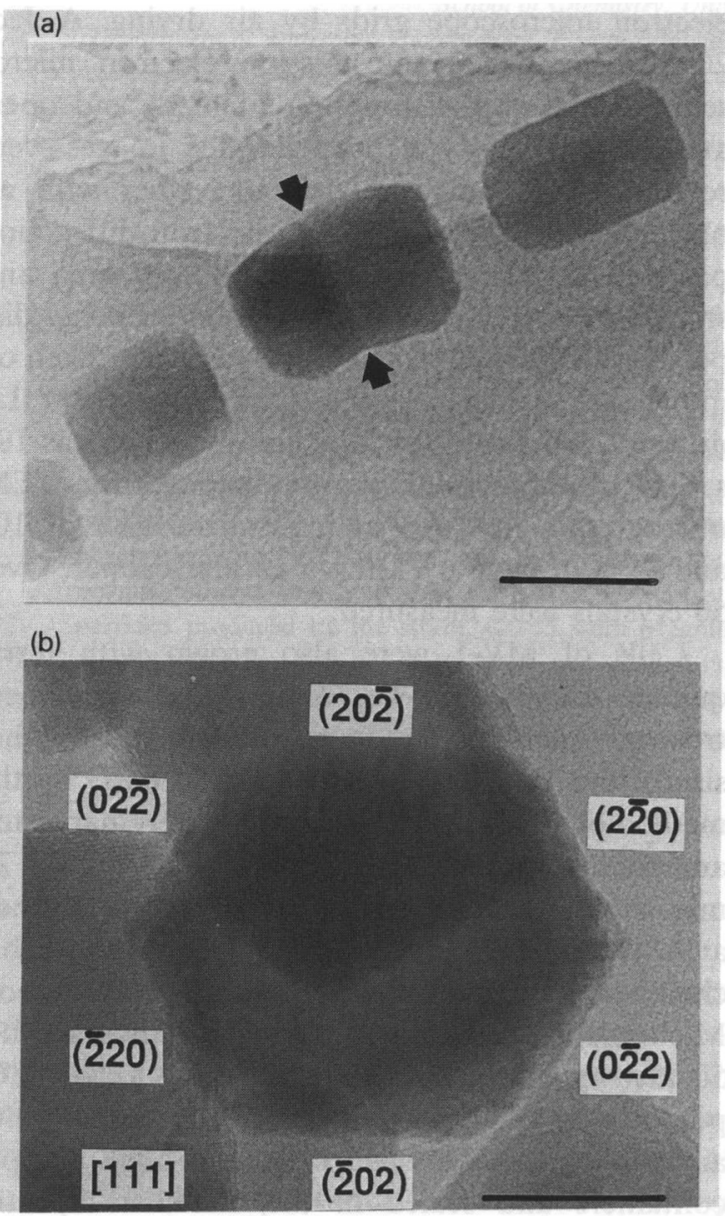

Fig. 1. (a) Transmission electron micrograph of magnetosomes aligned parallel to the long axis of a MV-1 cell. The chain direction corresponded to the crystallographic [111] axis. The arrowed crystal shows a twin plane oriented parallel to the end capping faces which are of the form $\{111\}$. Bar marker $=50$ $\mathrm{nm}$. (b) Lattice image of a MV-1 inclusion viewed in cross-section (i.e. along the [111] crystallographic direction) showing a hexagonal morphology based on $\{220\}$ faces. Fringes correspond to (220) (2.967 $\AA$ ) spacing. The fringes disappear in one half of the crystal due to the presence of an overlapping crystal. Bar marker $20 \mathrm{~nm}$.

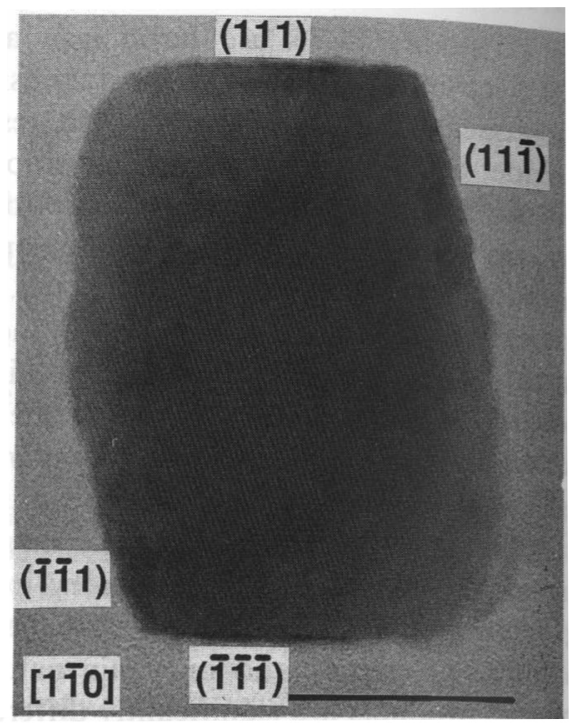

Fig. 2. Lattice image of MV-1 crystal viewed side-on along the crystallographic [1 10$]$ direction. Lattice fringes, $\{111\}(4.85 \AA)$. The top and bottom faces correspond to the (111) and (111)

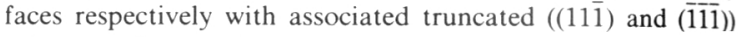
side faces. Bar marker $20 \mathrm{~nm}$.

Magnetite crystals produced by strain GS-15 were significantly different compared with the MV-1 particles. Individual particles from both the phosphate and carbonate-buffered systems were irregular rounded crystals with roughened surfaces (Figs. $4 \mathrm{a}$ and b). There was no evidence of cellular material either encapsulating or linking the particles.

The particles were measured (assuming an oval profile) along their long axis (length) and at right angles to that axis (width). The length of the carbonate-buffer particles (Fig. 5a) varied from 8.11 to $22.47 \mathrm{~nm}$ (mean value of $14 \mathrm{~nm}$ ), the phosphate-buffer particles (Fig. 5b) varied from 6.25 to $23.00 \mathrm{~nm}$ (mean value of $12 \mathrm{~nm}$ ). Particle width ranged from 5.81 to $15.72 \mathrm{~nm}$ (mean value of $11 \mathrm{~nm}$ ) for the carbonate sample (Fig. 5c) and from 5.33 to $20.16 \mathrm{~nm}$ (mean value of $10 \mathrm{~nm}$ ) for the phosphate-buffer sample (Fig. 5d).

The mineral phases deposited by cells of strains MV-1 and GS-15 were identified as magnetite $\left(\mathrm{Fe}_{3} \mathrm{O}_{4}\right)$ by a combination of energy dispersive $\mathrm{X}$-ray analysis, Mössbauer spectroscopy, and selected area/micro-electron diffraction. Energy dispersive X-ray analysis (data not shown) showed iron and oxygen to the only elements present in the crystals. Representative electron powder 

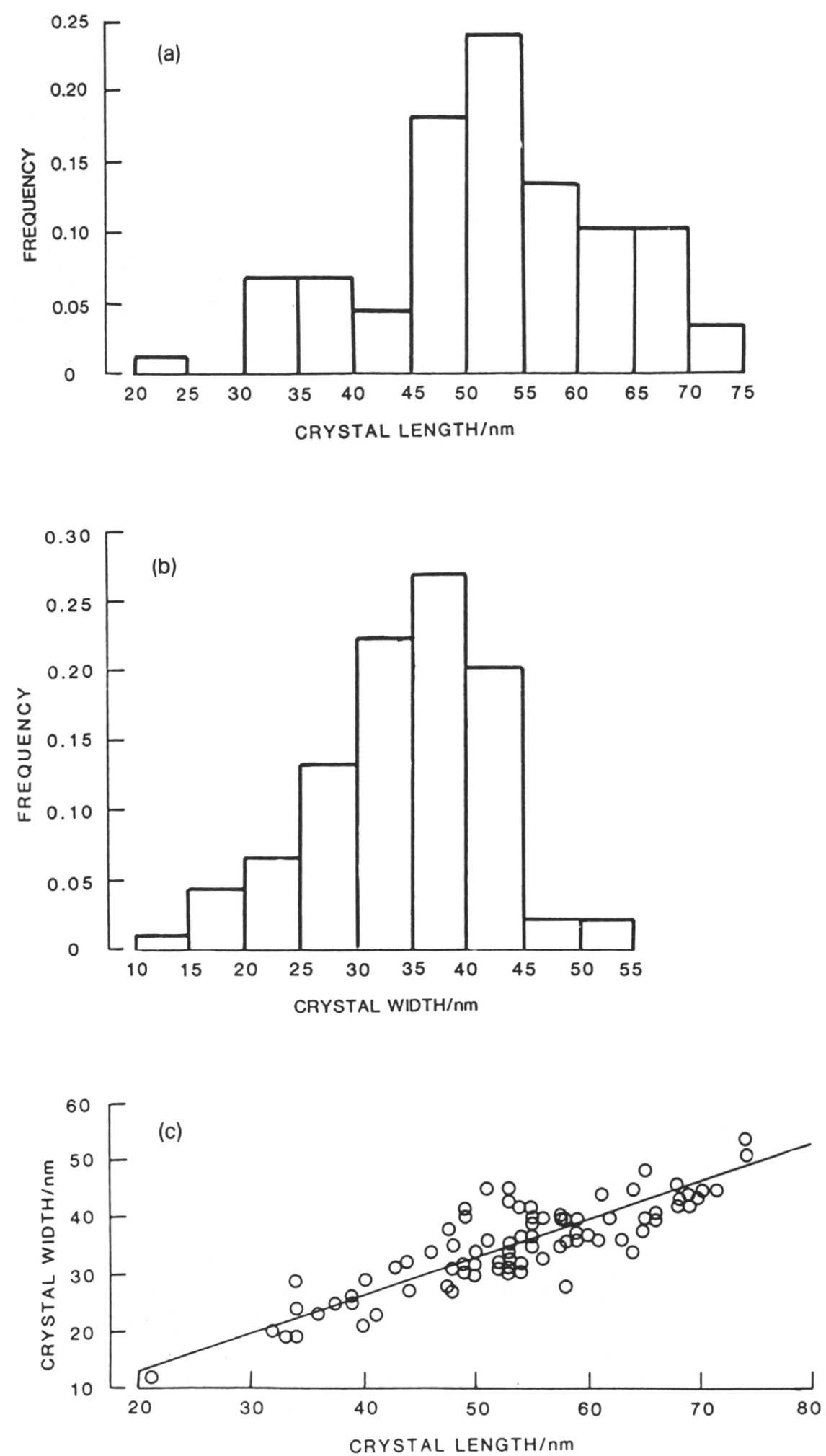

Fig. 3. (a) Histogram of MV-1 particle lengths. (b) Histogram of MV-1 particle widths. (c) Plot showing the linear relationship between crystal length and width. $(R=0.93)$. 
diffraction data for GS-15 crystals are shown in Table 1. For MV-1 particles single crystal electron diffraction patterns were obtained from individual magnetosomes. These were indexed on the basis of a magnetite cubic lattice with a unit cell parameter, $a=8.396 \AA$.

The single crystal electron diffraction patterns were consistent with the lattice images of individual MV-1 particles which showed fringe spacings corresponding to the $\{220\},\{111\}$ and $\{200\}$ lattice planes of magnetite. The angles between different sets of lattice fringes were consistent with the theoretical angles expected for the space

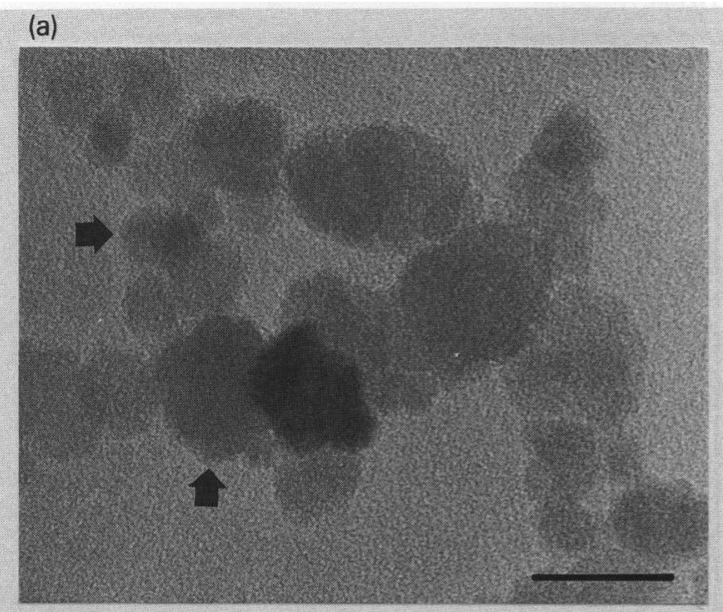

(b)

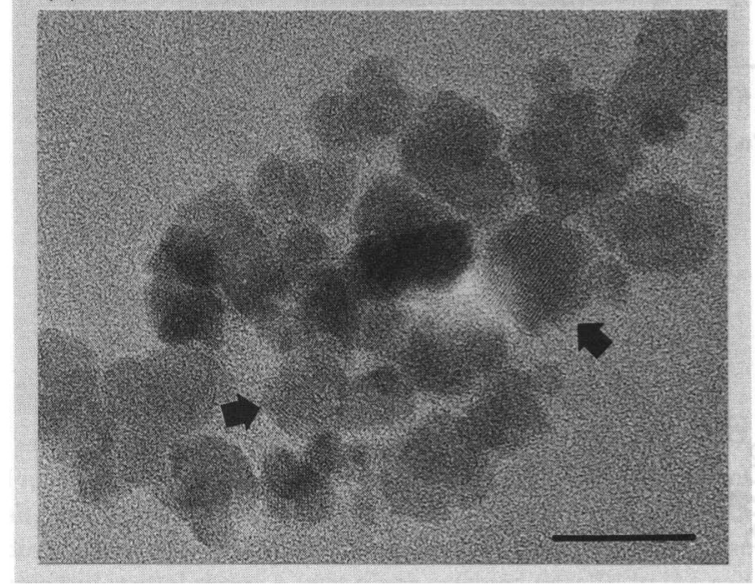

Fig. 4. (a) High resolution transmission electron micrograph showing GS-15 particles taken from the carbonate buffer. Lattice fringes, often ill-defined, can be seen in many particles (arrows). Bar marker $20 \mathrm{~nm}$. (b) High resolution transmission electron micrograph showing GS-15 particles taken from the phosphate buffer. As in the carbonate buffered sample the lattice fringes (arrows) are poorly-defined. Bar marker $20 \mathrm{~nm}$.
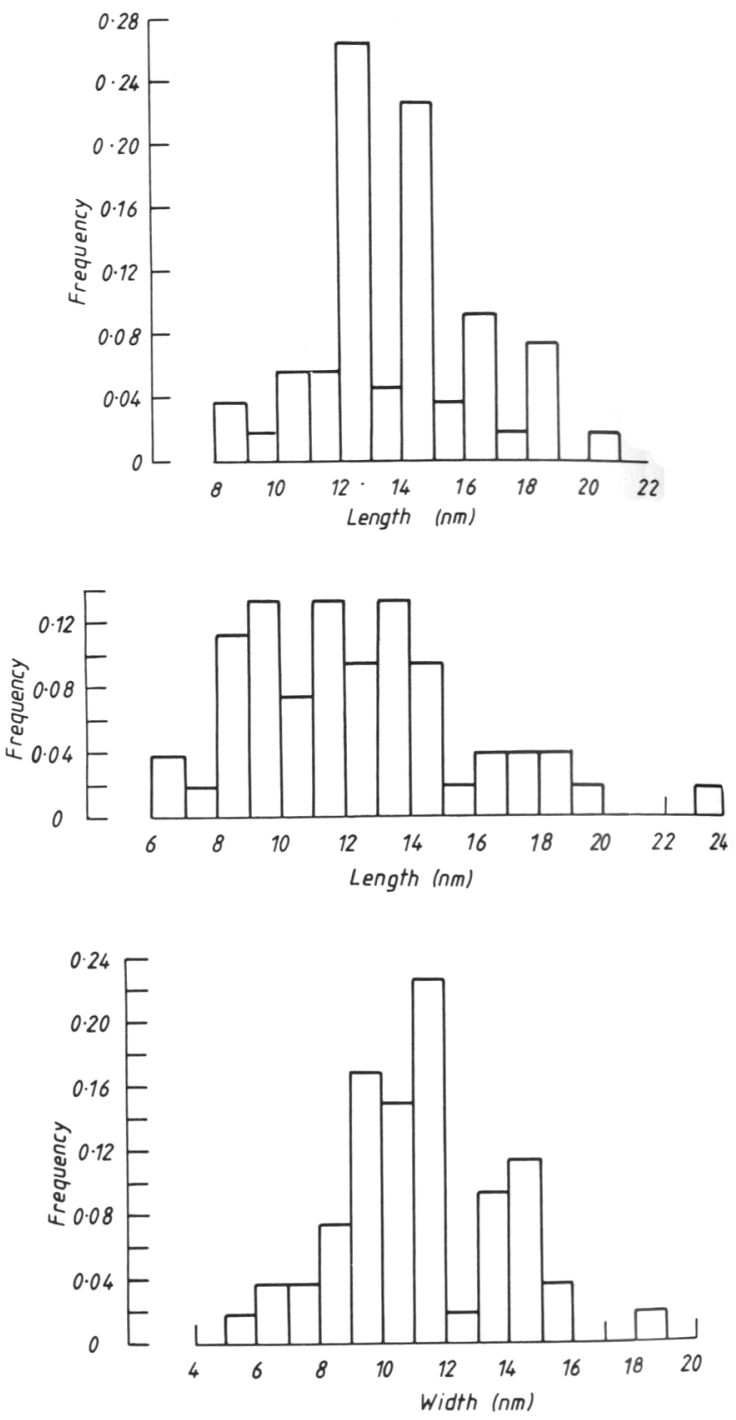

Fig. 5. (a) Histogram showing GS-15 particle length (carbonate buffer). $n=53, \sigma=3.02 \mathrm{~nm}$. (b) Histogram showing GS-15 particle length (phosphate buffer). $n=53, \sigma=3.40 \mathrm{~nm}$. (c) Histogram showing GS-15 particle width (carbonate buffer). $n=53, \sigma=2.51 \mathrm{~nm}$. (d) Histogram showing GS-15 particle width (phosphate buffer). $n=53, \sigma=2.90 \mathrm{~nm}$.

group $(\mathrm{Fd} 3 \mathrm{~m})$ of magnetite. Lattice fringes were well defined and continuous across the MV-1 crystals indicating that the particles were singledomain crystallites of high perfection (Figs. 1b and 2). There was no evidence for any amorphous phase within or overlying the MV-1 magnetite crystals.

Lattice fringes were a feature of approximately $30 \%$ of the particles in both GS-15 samples. The 
TABLE 1

Electron diffraction data for GS-15 crystals

\begin{tabular}{lll}
$\begin{array}{l}\text { Standard } \\
\text { magnetite }\end{array}$ & Sample & \\
\cline { 2 - 3 } & Phosphate & Carbonate \\
\hline $4.85(8)^{\mathrm{b}}$ & $2.970(220)^{\mathrm{c}}$ & $\begin{array}{l}\text { c } \\
2.820(111)^{\mathrm{c}}\end{array}$ \\
$2.967(30)$ & $2.519(311)$ & $2.522(311)$ \\
$2.532(100)$ & & \\
$2.424(8)$ & $2.061(400)$ & $2.104(400)$ \\
$2.099(20)$ & $1.715(422)$ & $1.714(422)$ \\
$1.715(10)$ & $1.619(511)$ & $1.614(511)$ \\
$1.616(30)$ & $1.479(440)$ & $1.487(440)$ \\
$1.485(40)$ & & \\
$1.419(2)$ & & $1.288(533)$ \\
$1.328(4)$ & $1.288(533)$ & $1.267(622)$ \\
$1.281(10)$ & $1.269(622)$ & \\
$1.266(10)$ & & $1.100(731)$ \\
$1.212(2)$ & &
\end{tabular}

ASTM card nos. 19-629, 24-804, 29-697.

${ }^{\mathrm{b}}$ Figure in parenthesis denotes X-ray diffraction intensity.

${ }^{c}$ Figure in parenthesis denotes hkl values.

fringes were continuous throughout the crystals (Figs. 4a and b) indicating that many particles were single crystals. However, few two-dimensional patterns were observed and the intensity of the fringes was often irregular suggesting that many crystals were not of high structural perfection. There was no evidence of crystal twinning. The failure of many particles to show lattice fringes suggests that they are either amorphous (e.g. residual ferrihydrite or $\mathrm{FeCO}_{3}$ ), or are crystalline but oriented out of diffraction alignment.

The three-dimensional morphology of MV-1 crystals was determined by a crystallographic analysis of lattice images recorded from crystals viewed along different directions. For example, the hexagonal edges observed in cross-section ran parallel to three sets of $\{200\}$ lattice fringes intersecting at $60^{\circ}$ (Fig. 1b). This image represents a view down the [111] axis of magnetite and indicates that the long axis of the crystal corresponded to the [111] direction. When viewed along the [110] crystal projection (Fig. 2) fringes corresponding to the $\{111\}$ and $\{200\}$ planes were observed with angles of $110^{\circ}((111) \wedge(11 \overline{1}))$ and $125^{\circ}$ $((111) \wedge(200))$. In this projection the crystals appeared as truncated rectangles, capped with smooth (111) and (111) faces and truncated by faces of index $(11 \overline{1})$ and $(\overline{1} \overline{1} 1)$. The angle between the well-defined capping and truncating faces was $110^{\circ}$, matching exactly the theoretical angle. Crystals viewed down the [211] zone (data not shown) had atomically smooth $\{110\}$ side edges. The apparent roughened surface of the long side edges shown in Fig. 2 arises because these faces do not lie parallel to the $[1 \overline{1} 0]$ projection of the magnetite structure.

These results can be interpreted on the basis of morphology comprising a hexagonal prism of $\{110\}$ faces which are capped and truncated by $\{111\}$ end faces (Fig. 6). A similar morphology was determined by Matsuda et al. [6] for magnetite crystals from an unidentified magnetotactic coccoid.

The Mössbauer spectra at $200 \mathrm{~K}$ and $10 \mathrm{~K}$ of intact MV-1 cells are shown in Fig. 7. The $200 \mathrm{~K}$ spectrum is principally that of pure, stoichiometric magnetite. The low intensity quadrupole doublet near zero velocity is due to hydrous ferric oxide, a precursor to magnetite precipitation in other magnetotactic bacteria [5,12]. The $10 \mathrm{~K}$ spectrum shows magnetite below the Verwey transition, a structural and electronic transition that occurs between $110 \mathrm{~K}$ and $120 \mathrm{~K}$ in bulk magnetite. The crossover from the high-temperature spectrum to the low-temperature spectrum (data not shown) occurred at about $110 \mathrm{~K}$. Thus the Mössbauer

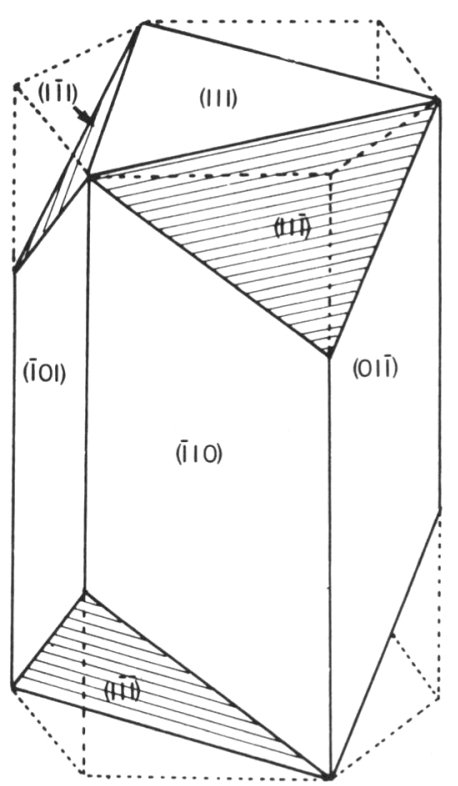

Fig. 6. Idealised crystal morphology for anisometric magnetic crystals from the species MV-1. 


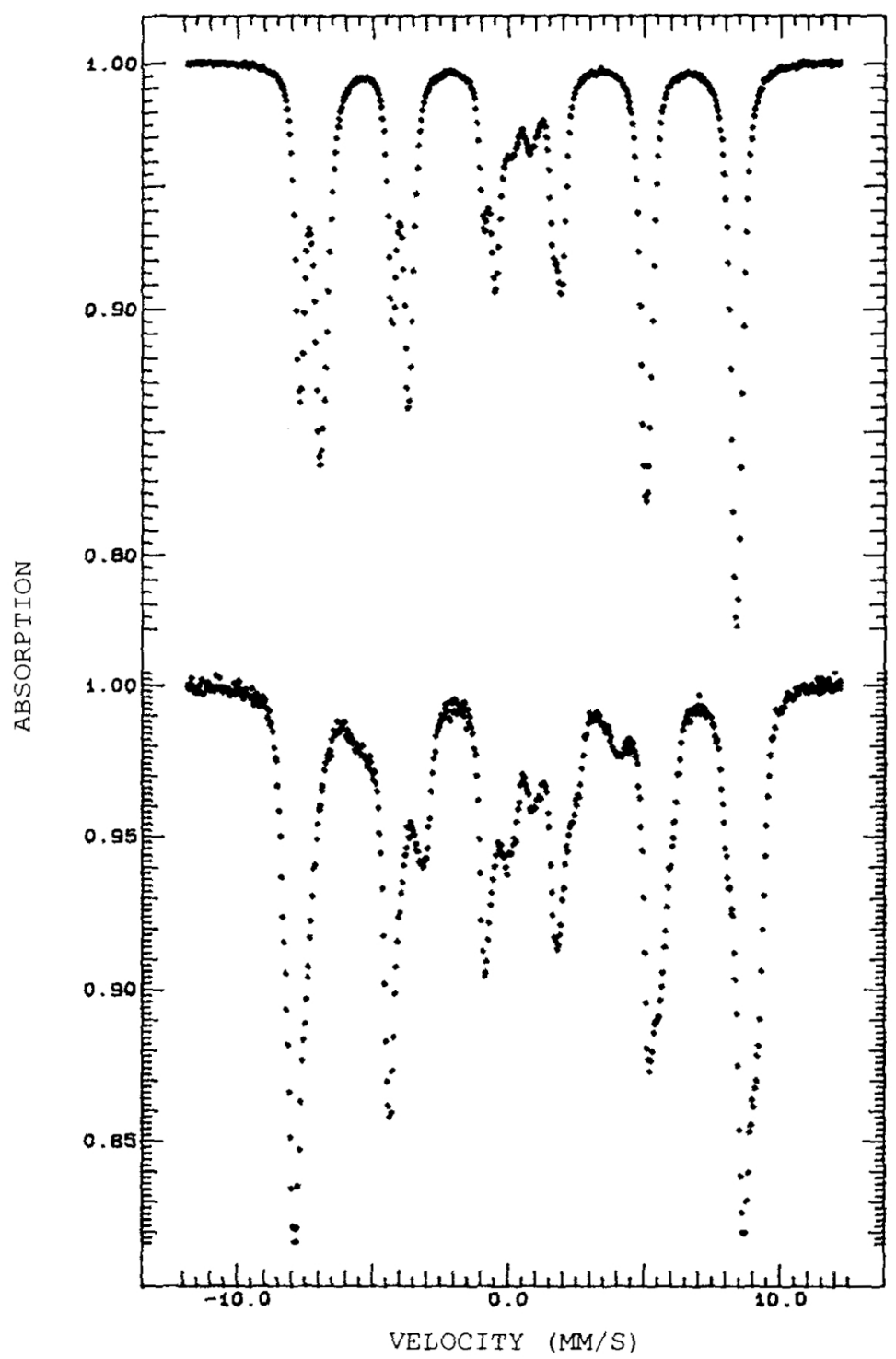

Fig. 7. Mössbauer spectra of MV-1 cells at $200 \mathrm{~K}$ (top) and $10 \mathrm{~K}$ (bottom).

data show that the magnetosomes of MV-1 contain mainly pure stoichiometric magnetite. Previous Mössbauer measurements of extracted magnetosomes from MV-1 indicated some oxidation of the magnetite particles to maghemite $\left(\gamma-\mathrm{Fe}_{2} \mathrm{O}_{3}\right)$ on exposure to atmospheric $\mathrm{O}_{2}$ [9].

Mössbauer spectra of particles produced by GS-15 grown in either a carbonate or a phosphate buffered medium are shown in Fig. 8 . The spectra are consistent with small particles of $\mathrm{Fe}_{3} \mathrm{O}_{4}$ in both cases. In the carbonate buffered medium there are extra lines in the Mössbauer spectrum at 0.4 and $2.3 \mathrm{~mm} / \mathrm{s}$ that correspond to ferrous carbonate [13]. These lines split below $35 \mathrm{~K}$, consistent with the ferrous carbonate magnetic ordering temperature of $38 \mathrm{~K}$ (data not shown). The lines are absent in the spectrum of magnetite produced in the phosphate buffer. These results are consistent with a process in which the organism reduces hydrous ferric oxide, and exports the resulting ferrous ions into the environment where they interact with excess hydrous ferric oxide to produce magnetite and, in the case of the carbonate buffer, with excess carbonate anions to produce ferrous carbonate. The absence of diffraction lines corresponding to ferrous carbonate (Ta- 


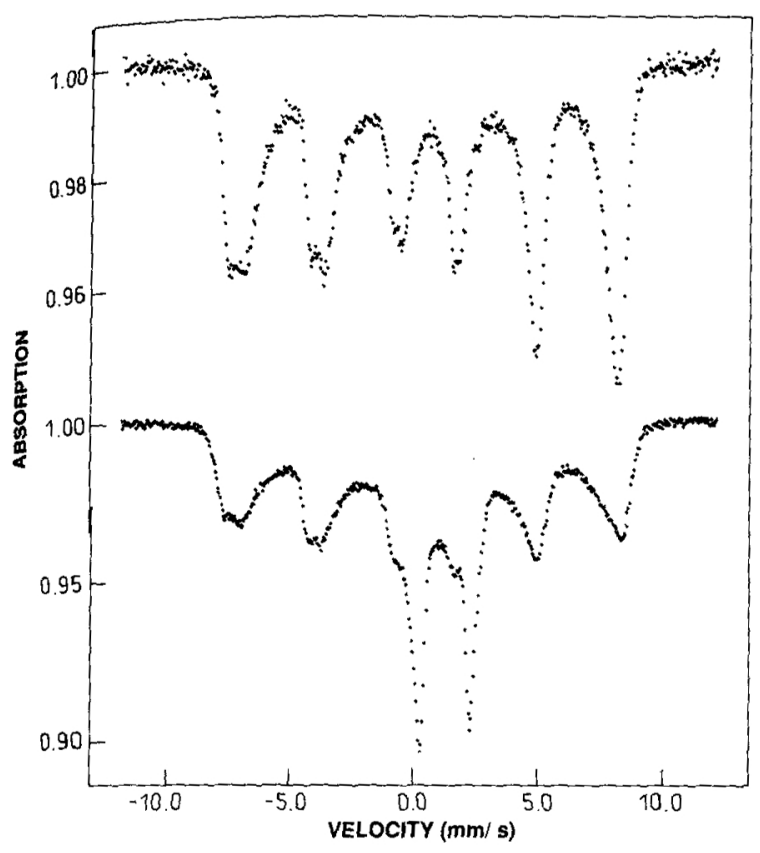

Fig. 8. Mössbauer spectra at $200 \mathrm{~K}$ of magnetite produced by GS-15 in phosphate buffer (top) and carbonate buffer (bottom).

ble 1) suggested that this material was present as a non-crystalline material.

\section{Discussion}

Bacterial strains GS-15 and MV-1 both form magnetite under anaerobic conditions, but the nature of the particles differs significantly. The crystals produced by cells of strain MV-1 are uniform in size, morphologically specific and of high structural perfection whereas the particles associated with strain GS-15 are irregular in shape, relatively small $(5-23 \mathrm{~nm})$ and structurally ill-defined. These differences result from the degree of crystallochemical control exerted by the organism over crystal synthesis. The species-specific crystals produced by MV-1 are matched to their functional requirement as organelles responsible for magnetotactic behaviour. In this respect, the particle size range of $\mathrm{MV}-1$ crystals falls within that required for single domain remanent magnetization $(35-100 \mathrm{~nm})$ [14], whereas the smaller GS-15 crystals are superparamagnetic. The latter behaviour results in the spectral broadening, caused by relaxation effects, observed in the Mössbauer spectra (Fig. 8). This is also consistent with recent magnetic data on these particles that indicate a broad distribution of particles sizes below the room temperature, permanent, single magnetic domain size range of ca. $35 \mathrm{~nm}$ [15].

The alignment of MV-1 magnetite particles in a chain results in the total magnet moment of the cell being equal to the sum of the moments of the individual particles. As magnetite has a saturation magnetisation of $480 \mathrm{emu} \mathrm{cm}^{-3}$ the magnetic moment of an average $(53 \times 35 \times 35 \mathrm{~nm}) \mathrm{MV}-1$ crystal is $3.11 \times 10^{-14}$ emu. This single crystal value compares with values of $6 \times 10^{-14} \mathrm{emu}$ and $5.5 \times 10^{-14} \mathrm{emu}$ for crystals from the bacterium MS-1 [16] and an unidentified bacterium [8] respectively. Assuming an average of ten magnetosomes per MV-1 cell, the permanent magnetic dipole moment per cell would be $3.11 \times 10^{-13}$ emu. This is consistent with an average measured magnetic dipole moment of $2.1 \times 10^{-13}$ emu for cells with an average of ten magnetosomes per cell [9] and is sufficient for the magnetotactic response [17].

The precise crystallochemical control over magnetite formation in cells of strain MV-1 compared with those of strain GS-15 indicates that the mineralization environment is strictly defined. Although not yet determined for MV-1 magnetosomes, magnetite crystals in other magnetotactic organisms have been shown to be surrounded by an organic membrane $[3,8]$. Isolating the site of crystal nucleation and growth in this way enables control to be exerted over ion diffusion, redox, $\mathrm{pH}$ and the spatial dimensions of mineralization.

The occurrence of the central twin plane and the presence of symmetry-related atomically smooth $\{111\}$ capping/truncating faces in both immature (ca. $10 \mathrm{~nm}$ wide) and mature inclusions indicates that the crystal growth mechanism in MV-1 is primarily centrosymmetric, rather than the apparent unidirectional growth of the bulletshaped anisometric crystals found in cells of an unidentified freshwater bacterium [18]. The MV-1 crystals also differ from those of this bacterium in that there is no apparent initial isotropic growth phase [18]. Thus crystallographic control is present even in the very early MV-1 crystals.

By comparison the crystals associated with GS15 serve no specialized cellular function. They are formed by the reaction of ferrous ions, generated 
by microbial reduction, with excess hydrated ferric oxide present in the external environment. The formation of magnetite by GS-15 is therefore more akin to a biologically-induced rather than a biologically-controlled mineralization process. This is reflected in the irregular morphology and relatively small size of the crystals, which are features characteristic of rapid, uncontrolled growth. In addition, the similarity of the crystals produced when GS-15 is grown in either phosphate or carbonate buffered medium suggests that they are formed by the same non-specific process.

In many respects, the extracellular bacterial magnetite produced by GS-15 bears a closer resemblance to soil magnetites of authigenic origin [19], or synthetic magnetites formed at low temperatures and neutral pH (20), than the intracellular magnetites produced by MV-1. Not only are the soil magnetites of a comparable size and morphology to that formed by GS-15 but they exhibit the same random particle aggregation. Intracellular magnetites, in contrast, often maintain their crystallographic alignment even within sediments [1].

Finally, this study shows that examination of separated magnetite particles from sediments by electron microscopy as well as low-temperature magnetic remanence measurements [15] can determine whether magnetotactic or dissimilatory non-reducing bacteria are responsible for the magnetic remanence observed in anaerobic sediments [21].

\section{Acknowledgements}

We thank Dr. T.C. Hollocher for use of the anaerobic chamber at Brandeis University. This is contribution number 6956 of te Woods Hole Oceanographic Institution. NHCS was supported by SERC Advanced Fellowship 85616. DAB and HWJ were supported by NSF grant OCE 87-581. RBF was supported by NSF grant DBM-8902474.

\section{References}

1 J.F. Stolz, S.-B.R. Chang and J.L. Kirschvink, Magnetotactic bacteria and single-domain magnetite in hemipelagic sediments, Nature 321, 849-851, 1986.

2 N. Peterson, T. von Dobeneck and H. Vali, Fossil bacterial magnetite in deep-sea sediments from the South Atlantic Ocean, Nature 320, 611-615, 1986.
3 D.L. Balkwill, D. Maratea and R.P. Blakemore, Ultrastruc. ture of a magnetotactic spirillum, J. Bacteriol. 141, 1399. 1408, 1980.

4 D.R. Lovley, J.F. Stolz, G.L. Nord Jr. and E.J.P. Philips, Anaerobic production of magnetite by a dissimilatory iron-reducing microorganism, Nature 330, 252-254, 1987.

5 S. Mann, R.B. Frankel and R.P. Blakemore, Structure, morphology and crystal growth of bacterial magnetite, $\mathrm{Na}$ ture 310, 405-407, 1984.

6 T. Matsuda, J. Endo, N. Osakabe and A. Tonomura, Morphology and structure of biogenic magnetite particles, Nature 302, 411-412, 1983.

7 S. Mann, T.T. Moench and R.J.P. Williams, A high resolution electron microscopic investigation of bacterial magnetite. Implications for crystal growth, Proc. R. Soc. London, Ser. B 221, 385-393, 1984.

8 S. Mann, N.H.C. Sparks and R.P. Blakemore, Ultrastructure and characterization of anisotropic magnetic inclusions in magnetotactic bacteria. Proc. R. Soc. London, Ser. B 231, 469-476, 1987.

9 D.A. Bazylinski, R.B. Frankel and H.W. Jannasch, Anaerobic magnetite production by a marine magnetotactic bacterium, Nature 334, 518-519, 1988.

10 R.P. Blakemore, D. Maratea and R.S. Wolfe, Isolation and pure culture of a freshwater magnetic spirillum in chemically defined medium, J. Bacteriol. 140, 720-729, 1979.

11 D.R. Lovley and E.J.P. Phillips, Novel mode of microbial energy metabolism: organic carbon oxidation coupled to dissimilatory reduction of iron or manganese, Appl. Environ. Microbiol. 54, 1472-1480, 1988.

12 R.B. Frankel, G.C. Papaefthymiou, R.P. Blakemore and W. O'Brien, $\mathrm{Fe}_{3} \mathrm{O}_{4}$ precipitation in magnetotactic bacteria, Biochim. Biophys. Acta 763, 147-159, 1983.

13 N.N. Greenwood and T.C. Gibb, Mössbauer Spectroscopy, Chapman and Hall, London, 1972.

14 R.F. Butler and S.K. Banerjee, Theoretical single domain grain size in magnetite and titanomagnetite, J. Geophys. Res. 80, 4049-4058, 1975.

15 B.M. Moskowitz, R.B. Frankel and D.R. Lovley, A comparison of magnetite particles produced anaerobically by magnetotactic and dissimilatory iron-reducing bacteria, Geophys. Res. Lett. 16, 665-668, 1989.

16 R.B. Frankel and R.P. Blakemore, Navigational compass in magnetic bacteria, J. Magn. Mater. 15-18, 1562-1564, 1980.

17 R.B. Frankel, Magnetic guidance of organisms, Annu. Rev. Biophys. Bioeng. 13, 85-103, 1984.

18 S. Mann, N.H.C. Sparks and R.P. Blakemore, Structure, morphology and crystal growth of anisotropic magnetite crystals in magnetotactic bacteria, Proc. R. Soc. London, Ser. B, 477-487, 1987.

19 B.A. Mahler and R.M. Taylor, Formation of ultrafinegrained magnetite in soils, Nature 336, 368-370, 1988.

20 S. Mann, N.H.C. Sparks, S.B. Couling, M.C. Larcombe and R.B. Frankel, Crystallochemical characterization of magnetic spinels prepared from aqueous solution, J. Chem. Soc. Farad., 85, 3033-3045, 1989.

21 R. Karlin, M. Lyle and G.R. Heath, Authigenic magnetite formation in suboxic marine sediments, Nature 326, 490493, 1987. 